\title{
Proposal To Reclassify Zoogloea ramigera IAM 12670 (P. R. Dugan 115) as Duganella zoogloeoides gen. nov., sp. nov. AKIRA HIRAISHI,${ }^{1,2 *}$ YONG KOOK SHIN, ${ }^{1} \dagger$ AND JUNTA SUGIYAMA ${ }^{1}$ Institute of Molecular and Cellular Biosciences, The University of Tokyo, Bunkyo-ku, Tokyo 113, ${ }^{1}$ and Department of Ecological Engineering, Toyohashi University of Technology, Tenpaku, Toyohashi $441,{ }^{2}$ Japan
}

\begin{abstract}
The taxonomic position of a misclassified strain, Zoogloea ramigera IAM $12670^{\mathrm{T}}\left(=\mathrm{ATCC}_{25925^{\mathrm{T}}}=\mathbf{P} . \mathbf{R}\right.$. Dugan $115^{\mathrm{T}}$ ), was reevaluated. A phylogenetic analysis based on 16S ribosomal rDNA sequences revealed that this organism was located in the beta subclass of the class Proteobacteria with members of the genus Telluria as its closest relatives. On the basis of phenotypic and phylogenetic information, we propose that this organism should be reclassified in a new taxon with the name Duganella zoogloeoides gen. nov., sp. nov.
\end{abstract}

Zoogloea ramigera, which is at this time the only species of the genus Zoogloea Itzigsohn 1868, is an aerobic, chemoorganotrophic, gram-negative, rod-shaped bacterium that forms characteristic cell aggregates surrounded by gelatinous matrices, the so-called zoogloeal matrices. This organism has been isolated from wastewater environments, such as activated sludge and trickling filters, and it has been suggested that $Z$. ramigera plays an important role in these environments. The following three strains of $Z$. ramigera have historically been well-known through a number of experimental studies: type strain ATCC19544 (= N. C. Dondero 106) (22), ATCC 19623 (= K. T. Crabtree I-16-M) (2), and ATCC $25935^{\mathrm{T}}$ (= P. R. Dugan $\left.115^{\mathrm{T}}\right)(4,6,12)$. During studies to taxonomically revise $Z$. ramigera, however, $\mathrm{Unz}(22,23)$ mentioned that there were major phenotypic differences among these three strains of $Z$. ramigera and that strains ATCC 19623 and ATCC $25935^{\mathrm{T}}$ should be removed from the genus Zoogloea. Recent research on polyamine patterns (8), fatty acid and quinone profiles (9), and $16 \mathrm{~S}$ ribosomal DNA (rDNA) sequences of Zoogloea strains $(17,19)$ provided evidence that there has been chemotaxonomic and phylogenetic divergence between $Z$. ramigera ATCC $19544^{\mathrm{T}}$ and the other two strains. The chemotaxonomic and phylogenetic data, together with the earlier phenotypic information, led to a reevaluation of the taxonomic criteria for identification of $Z$. ramigera and emendation of the genus Zoogloea (19). The data require that each of the misnamed $Z$. ramigera strains be reclassified as a member of an appropriate known genus or a new genus. Here we report the results of a reexamination of one of the misnamed strains, strain IAM $12670^{\mathrm{T}}$ (= ATCC $25935^{\mathrm{T}}$ ), and propose that this bacterium should be reclassified as a strain of Duganella zoogloeoides gen. nov., sp. nov.

Strain IAM $12670^{\mathrm{T}}$ was obtained from the Culture Collection Center of the Institute of Applied Microbiology (now IAM Culture Collection, Institute of Molecular and Cellular Biosciences), The University of Tokyo, Tokyo, Japan. After several transfers of the strain on agar media, two morpholog-

\footnotetext{
* Corresponding author. Mailing address: Department of Ecological Engineering, Toyohashi University of Technology, Tenpaku, Toyohashi 441, Japan. Phone: 81-532-44-6913. Fax: 81-532-44-6929.

$\dagger$ Present address: Korean Collection for Type Cultures, Genetic Resources Center, Korea Research Institute of Bioscience \& Biotechnology, Korea Institute of Science \& Technology, Taejon 305-333, Korea.
}

ical groups of colonies appeared and were designated strains $12670 \mathrm{~A}$ and $12670 \mathrm{~B}$. The colonies of strain 12670A, which accounted for more than $70 \%$ of the colonies recovered, were glistening, convex with entire margins, viscous, and cream to straw colored. The viscous appearance of this strain became more pronounced with time of incubation. The colonies of strain $12670 \mathrm{~B}$ were tough, leathery, dry, wrinkled, and pale yellow. We examined both of the newly isolated clones in this study. All phenotypic tests, DNA-DNA hybridization assays, and $16 \mathrm{~S}$ rDNA sequencing were performed as previously described $(9-11,19)$. A distance matrix tree based on 16S rDNA sequences was constructed by the neighbor-joining method (18) with the CLUSTAL W program (21). Randomly amplified polymorphic DNA (RAPD) analysis $(24,27)$ was performed with a Ready-To-Go RAPD analysis kit (Pharmacia, Uppsala, Sweden) and with crude cell lysates as sources of template DNA; these crude cell lysates were prepared by a previously described protocol (11). The PCR primers used were the following six RAPD primers offered as a set by the manufacturer: primer 1, 5'-GGTGCGGGAA-3'; primer 2, 5'-GTTTCGCT CC-3'; primer 3, 5'-GTAGACCCGT-3'; primer 4, 5'-AAGA GCCCGT-3'; primer 5, 5'-AACGCGCAAC-3'; and primer 6, 5'-CCCGTCAGCA-3'. The RAPD reaction and detection of RAPD patterns by gel electrophoresis were performed according to the manufacturer's instructions.

The two strains that were repurified differed in floc formation in addition to colony appearance. Strain 12670A exhibited dispersed growth with no or little formation of visible flocs when it was cultured with shaking in complex liquid media containing peptone. This strain formed visible flocs only when it was grown in chemically defined medium supplemented with organic acids, such as tartrate, as the sole carbon source. The flocs formed were amorphous. On the other hand, strain $12670 \mathrm{~B}$ constantly produced cell aggregates both in complex media and in chemically defined media. The flocs formed by this strain were amorphous but, as is the case in "typical" Zoogloea strains, were fingerlike occasionally. Strains $12670 \mathrm{~A}$ and $12670 \mathrm{~B}$ were indistinguishable from each other in all other characteristics investigated, including cell morphology and physiological, biochemical, and chemotaxonomic characteristics (for details, see the descriptions of the genus and species below). The phenotypic studies indicated that the two strains were variants that originated from a single strain. Variations in colony appearance of the original strain, $Z$. ramigera $\mathbf{P}$. $\mathbf{R}$. Dugan $115^{\mathrm{T}}$, on agar media have been reported previously (4). 


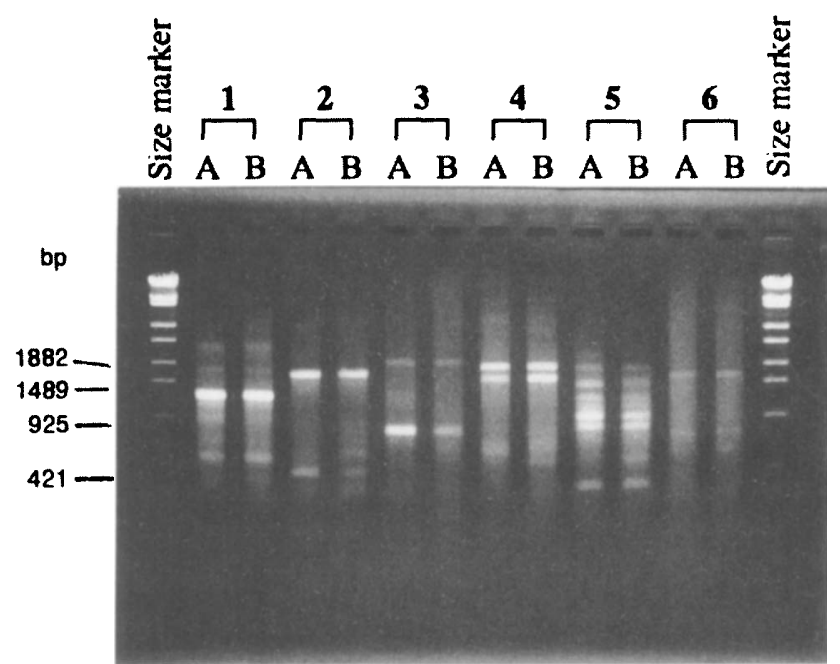

FIG. 1. RAPD patterns of strains $12670 \mathrm{~A}$ and $12670 \mathrm{~B}$. The patterns obtained with arbitrary PCR primers 1 to 6 (indicated at the top) are shown. Lanes A and $\mathrm{B}$ contained strains $12670 \mathrm{~A}$ and $12670 \mathrm{~B}$, respectively. PCR products were separated by gel electrophoresis ( $2 \%$ agarose) and were detected by ethidium bromide straining. Size marker, $\lambda$-EcoT14 I digest.

Also, studies with typical $Z$. ramigera strains have shown that nonflocculating variants appear spontaneously upon subculture $(20)$.

We confirmed the genetic homogeneity of strains $12670 \mathrm{~A}$ and $12670 \mathrm{~B}$ by DNA-DNA hybridization studies, as they showed 93 to $102 \%$ hybridization to each other in two different assays. The guanine-plus-cytosine contents of the genomic DNAs of the two strains varied from 63.4 to $63.8 \mathrm{~mol} \%$, but the variations appeared to be within the range of analytical error. We also found that the small-subunit rRNA structures of the two strains were identical. Moreover, there was no difference between the two strains in their RAPD patterns with the six arbitrary PCR primers (Fig. 1), suggesting that they were derived from the same strain.

The 16S rDNA sequence analysis of strain IAM $12670^{\mathrm{T}}$ performed in this study revealed that there were some errors in the sequence for the strain previously reported by us (DDBJ, EMBL, and GenBank accession no. D14256) (19). Our revised sequence for strain IAM $12670^{\mathrm{T}}$ differed at only one position from the sequence of strain ATCC $25935^{\mathrm{T}}$ published by Rossello-Mora et al. (accession no. X74914) (17). Previous phylogenetic studies have indicated that strain IAM $12670^{\mathrm{T}}$ $\left(=\right.$ ATCC $25935^{\mathrm{T}}$ ), as well as $Z$. ramigera ATCC $19544^{\mathrm{T}}$, belong to the beta subclass of the class Proteobacteria, but that within this subclass, the two strains form different clusters at the generic level $(17,19)$. We reconstructed a phylogenetic tree based on the updated 16S rDNA sequence information for these $Z$. ramigera strains and their phylogenetic relatives available from The Ribosomal Database Project database (14) and the DDBJ, EMBL, and GenBank databases. As shown in Fig. 2 , the type strain of $Z$. ramigera formed a cluster with the phototrophic bacterium Rhodocyclus purpureus, whereas strain IAM $12670^{\mathrm{T}}$ was located in a different cluster with members of the genus Telluria (1) as its closest relatives. The IAM $12670^{\mathrm{T}}$ Telluria cluster also formed a lineage with the poly(3-hydroxybutyrate)-degrading organism Pseudomonas lemoignei $(3,15)$ as a sister group. The levels of corrected distance (13) were 0.0577 to 0.0650 between strain IAM $12670^{\mathrm{T}}$ and the Telluria species and 0.0696 between strain IAM $12670^{\mathrm{T}}$ and $P$. lemoignei. These values may be low enough to separate strain IAM
$12670^{\mathrm{T}}$ from its recognized phylogenetic neighbors at the generic level.

On the basis of phenotypic, chemotaxonomic, and phylogenetic evidence noted above and elsewhere $(8,17,19,23)$, we propose that $Z$. ramigera IAM $12670^{T}$ should be reclassified as a member of a new genus and new species with the name Duganella zoogloeoides. Differential characteristics of D. zoogloeoides and phylogenetically and phenotypically related organisms are summarized in Table 1. Although our proposal allows the existence of only one strain in the new genus at this time, this is reasonable considering the necessity for avoiding further confusion in Zoogloea taxonomy and also the importance of the strain in the field of wastewater microbiology and biotechnology (4).

A number of strains that show high levels of $16 \mathrm{~S}$ rDNA sequence similarity to $D$. zoogloeoides have recently been isolated from soil (16). The partial 16S rDNA sequences (ca. 500 bases) of these new strains (DDBJ, EMBL, and GenBank accession no. D84564, D84572, D84574, D84576, and D84577) have similarity levels of 96.7 to $98.1 \%$ with the sequence of D. zoogloeoides IAM $12670^{\mathrm{T}}$, suggesting that all of these organisms may form a phylogenetically coherent group at the generic level. Further study of the new soil strains noted above should provide more criteria to circumscribe the new genus Duganella. Also, the $D$. zoogloeoides description should be-

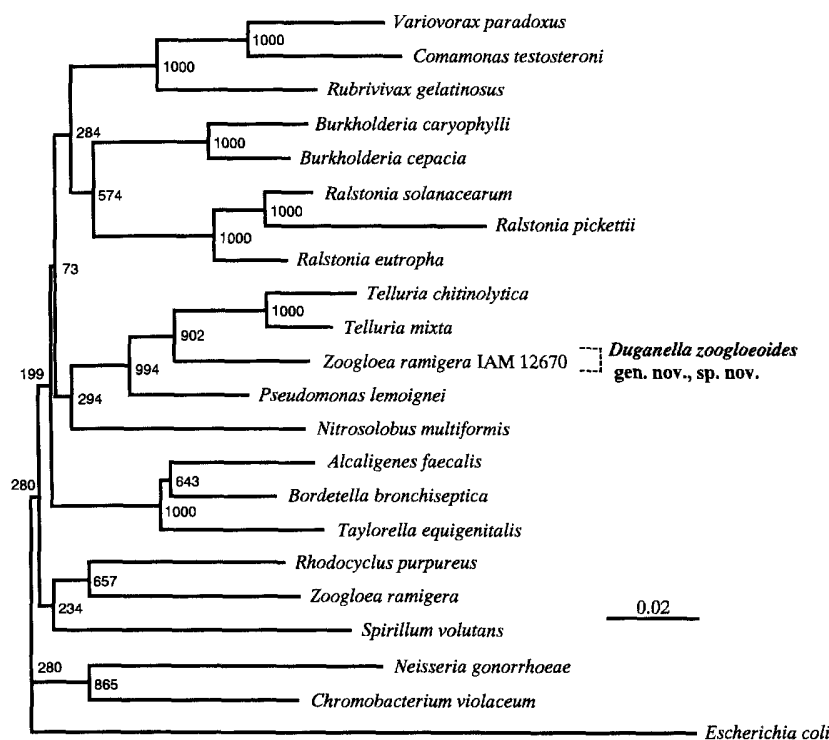

FIG. 2. Phylogenetic tree derived from an analysis of the 16S rDNA sequences of strain IAM $12670^{\mathrm{T}}$ and related organisms belonging to the beta subclass of the class Proteobacteria. The sequence of Escherichia coli was used as an outgroup to root the tree. Bootstrap confidence values obtained with 1,000 resamplings (5) are given at branch points. Scale bar indicates 2 nucleotide substitutions per 100 nucleotides. The reference organisms and the accession numbers for their $16 \mathrm{~S}$ rDNA and rRNA sequences used in the phylogenetic analysis are as follows: Alcaligenes faecalis ATCC $8750^{\mathrm{T}}$, M22508; Bordetella bronchiseptica ATCC $19395^{\mathrm{T}}$, U04948; Burkholderia caryophylli ATCC $25418^{\mathrm{T}}$, X67039; Burkholderia cepacia ATCC $25416^{\mathrm{T}}$, M22518; Chromobacterium violaceum ATCC $12472^{\mathrm{T}}$, M22510; Comamonas testosteroni ATCC $11996^{\mathrm{T}}, \mathrm{M}_{11224}$ Escherichia coli, J01695; Neisseria gonorrhoeae NCTC 8375 ${ }^{\mathrm{T}}$, X07714; Nitorosolobus multiformis ATCC $25196^{\mathrm{T}}$, L35509; Pseudomonas lemoignei LMG $2207^{\mathrm{T}}$, X92554; Ralstonia eutropha ATCC $17697^{\mathrm{T}}$, M32021; Ralstonia pickettii ATCC 27512, X67042; Ralstonia solanacearum PDDCC17127 ${ }^{\mathrm{T}}$, U28221; Rhodocyclus purpureus $6770^{\mathrm{T}}$, M34132; Rubrivivax gelatinosus ATCC $17011^{\mathrm{T}}$, D16213; Spirillum volutans ATCC 19554 ${ }^{\mathrm{T}}$, M34131; Taylorella equigenitalis NCTC $11184^{\mathrm{T}}$ X68645; Telluria chinolytica ACM 3522 ${ }^{\mathrm{T}}$, X65590; Telluria mixta ACM $1762^{\mathrm{T}}$, X65589; Variovorax paradoxus IAM $12373^{\mathrm{T}}$, D30793; and Zoogloea ramigera IAM $12136^{\mathrm{T}}$, D14254. 
TABLE 1. Differential characteristics of Duganella gen. nov. and related genera or species of the beta subclass of the class Proteobacteria ${ }^{a}$

\begin{tabular}{|c|c|c|c|c|c|c|c|c|}
\hline Characteristic & Duganella gen. nov. & Acidovarax & Burkholderia & Comamonas & P. lemoignei & Ralstonia & Telluria & Zoogloea \\
\hline Cell diam $>1.0 \mu \mathrm{m}$ & - & - & - & $\mathrm{V}$ & - & - & - & + \\
\hline Flagellation & Polar (m) & Polar (m) & $\begin{array}{l}\text { Polar }(\mathrm{m}, \mathrm{t}) \\
\text { or none }\end{array}$ & Polar (t) & Polar (m) & $\begin{array}{l}\text { Polar }(m), \\
\text { per, or none }\end{array}$ & Mix, polar (m) & Polar $(\mathrm{m})$ \\
\hline Flocculent growth & + & - & - & - & - & - & - & + \\
\hline Growth on nutrient agar & + & + & + & + & - & + & - & $(+)$ \\
\hline Nondiffusible yellow pigment & + & - & - & - & - & - & $\mathrm{V}$ & - \\
\hline Diffusible pigment & - & - & + & - & - & $\mathrm{V}$ & - & - \\
\hline $\mathrm{H}_{2}$ autotrophy & - & $\mathrm{V}$ & - & - & - & $\mathrm{V}$ & - & - \\
\hline $\begin{array}{l}\text { Oxidative acid produced from } \\
\text { glucose }\end{array}$ & + & + & + & - & - & $\mathrm{V}$ & + & - \\
\hline Hydrolysis of starch & + & - & - & - & - & - & + & - \\
\hline Hydrolysis of gelatin & + & $\mathrm{V}$ & $\mathrm{V}$ & - & - & $\mathrm{V}$ & + & + \\
\hline Major respiratory quinone(s) & Q-8 & $\mathrm{Q}-8$ & Q-8 & Q-8 & & Q-8 & Q-8 & $\mathrm{Q}-8, \mathrm{RQ}-8$ \\
\hline Major 3-OH fatty acid(s) & $\mathrm{C}_{10: 0}$ & $\mathrm{C}_{10: 0}$ & $\mathrm{C}_{14: 0}, \mathrm{C}_{16: 0}$ & $\mathrm{C}_{10: 0}$ & $\mathrm{C}_{10: 0}$ & $\mathrm{C}_{14: 0}$ & & $\mathrm{C}_{10: 0}$ \\
\hline $\mathrm{G}+\mathrm{C}$ content of DNA ( $\mathrm{mol} \%)$ & $63-64$ & $62-66$ & $59-70$ & $60-69$ & 58 & $64-67$ & $67-72$ & $67-69$ \\
\hline
\end{tabular}

${ }^{a}$ Abbreviations: +, positive; $(+)$, weakly positive; -, negative; v, variable among species or strains; polar (m), polar monotrichous; polar ( $\mathrm{t}$ ), polar tuft; per, peritrichous; mix, mixed flagella; Q-8, ubiquinone with eight isoprene units; RQ-8, rhodoquinone with eight isoprene units. Information from references $1,3,7,15$, 19, 25,26 , and 28 and this study.

come much more valuable when the characteristics of these isolates are included.

Description of Duganella gen. nov. Duganella (Du.ga.nel'la. M.L. dim. ending -ella; M.L. fem. n. Duganella, named after P. R. Dugan, an American microbiologist who isolated the organism). The description of the genus is based on information from references 4, 8, 9, 19 and 23 and this study. Cells are gram-negative, non-spore-forming, motile rods. Aerobic chemoorganotrophs having a strictly respiratory type of metabolism with oxygen as the terminal electron acceptor. No chemolithotrophic growth occurs with molecular hydrogen. Amorphous or fingerlike flocculent growth occurs in liquid media. Mesophilic and neutrophilic. Growth is good on ordinary nutrient media and also occurs in mineral media supplemented with simple organic compounds as carbon and energy sources. Catalase and oxidase are present. Acid is produced oxidatively from glucose and other carbohydrates. Amylase, gelatinase, and urease are produced. Major components of the cellular fatty acids are $\mathrm{C}_{16: 0}$ and $\mathrm{C}_{16: 1}$, and $3-\mathrm{OH}-\mathrm{C}_{10: 0}$ is the major hydroxy fatty acid. Ubiquinone 8 is the sole respiratory quinone. Putrescine and hydroxyputrescine are intracellular polyamines. The $\mathrm{G}+\mathrm{C}$ content of the genomic DNA is 63 to 64 mol\%. The phylogenetic position is in the beta subclass of the class Proteobacteria, with members of the genus Telluria as phylogenetic neighbors. The type species is $D$. zoogloeoides.

Description of Duganella zoogloeoides sp. nov. Duganella zoogloeoides (zo.o.gloe.o'i.des. M.L. bacterial genus name Zoogloea; Gr. suf. -oides, similar to; M.L. adj. zoogloeoides, similar to Zoogloea). The characteristics are the same as those described above for the genus. Other properties, based on information from references 4,12 , and 23 and this study, are as follows. Cells are straight or slightly curved rods that are 0.6 to $0.8 \mu \mathrm{m}$ wide and 1.8 to $3.0 \mu \mathrm{m}$ long. Motile by means of single polar flagella. Colonies on nutrient agar media are glistening, convex with entire margins, viscous, and pale yellow to straw colored. Tough, leathery, dry, wrinkled colonies appear in some cases. Aerobic chemoorganotrophy is the mode of growth. Nitrate is not used as a terminal electron acceptor for growth; denitrification is negative. No growth factor is required for growth, but yeast extract stimulates growth. Forms an esterlike sweet odor in cultures with organic acids as carbon sources. Produces acid from and grows with the following carbohydrates (as carbon sources): L-arabinose, D-xylose, D-glucose, D-fructose, D-galactose, D-mannose, maltose, sucrose, cel- lobiose, lactose, and glycogen. Growth and acid production are negative with D-ribose, L-rhamnose, glycerol, D-mannitol, Dsorbitol, and inositol. Carbon sources other than carbohydrates that are utilized are pyruvate, citrate, succinate, fumarate, malate, malonate, tartrate, ethanol, alanine, aspartate, asparagine, glutamate, and proline. No growth or little growth occurs with formate, acetate, propionate, butyrate, caproate, caprylate, methanol, propanol, benzoate, $p$-hydroxybenzoate, glycine, histidine, arginine, lysine, ornithine, or tryptophan. Source: sewage and polluted water. The type strain is IAM $12670(=$ ATCC $25935=$ P. R. Dugan 115).

We thank H. G. Trüper for his valuable advice on nomenclature and etymology.

\section{REFERENCES}

1. Bowman, J. P., L. I. Sly, A. C. Hayward, Y. Spiegel, and E. Stackebrandt. 1993. Telluria mixta (Pseudomonas mixta Bowman, Sly, and Hayward 1988) gen. nov., comb. nov., and Telluria chitinolytica sp. nov., soil-dwelling organisms which actively degrade polysaccharides. Int. J. Syst. Bacteriol. 43:120124

2. Crabtree, K., and E. MaCoy. 1967. Zoogloea ramigera Itzigsohn, identification and description. Request for an Opinion as to the status of the generic name Zoogloea. Int. J. Syst. Bacteriol, 17:1-10.

3. Doudroff, M., and N. J. Palleroni. 1974. Genus Pseudomonas, p. 217-243. In R. E. Buchanan and N. E. Gibbons (ed.), Bergey's manual of determinative bacteriology, 8th ed. The Williams \& Wilkins Co., Baltimore, Md.

4. Dugan, P. R., D. L. Stoner, and H. M. Pickrum. 1992. The genus Zoogloea, p. 3952-3964. In A. Balows, H. G. Trüper, M. Dworkin, W. Harder, and K.-H. Schleifer (ed.), The prokaryotes, 2nd ed. Springer-Verlag, New York, N.Y.

5. Felsenstein, J. 1985. Confidence limits on phylogenies: an approach using the bootstrap. Evolution 39:783-791.

6. Friedman, B. A., and P. R. Dugan. 1968. Identification of Zoogloea species and the relationship to zoogloeal matrix and floc formation. J. Bacteriol. 95:1903-1909.

7. Gillis, M., V. Tran Van, R. Bardin, M. Goor, P. Hebbar, A. Willems, P. Segers, K. Kersters, T. Heulin, and M. P. Fernandez. 1995. Polyphasic taxonomy in the genus Burkholderia leading to an emended description of the genus and proposition of Burkholderia vietnamiensis sp. nov. for $\mathrm{N}_{2}$-fixing isolates from rice in Vietnam. Int. J. Syst. Bacteriol. 45:274-289.

8. Hamana, K., and S. Matsuzaki. 1993. Polyamine distribution patterns serve as a phenotypic marker in the chemotaxonomy of the Proteobacteria. Can. J. Microbiol. 39:304-310.

9. Hiraishi, A., Y. K. Shin, and J. Sugiyama. 1992. Isoprenoid quinones and fatty acids of Zoogloea. Antonie van Leeuwenhoek 61:231-236.

10. Hiraishi, A., Y. K. Shin, and J. Sugiyama. 1995. Brachymonas denitrificans gen. nov., sp. nov., a rhodoquinone-containing chemoorganotrophic bacterium, and evolutionary relationships of rhodoquinone producers to bacterial members with various quinone classes. J. Gen. Appl. Microbiol, 41:99-117.

11. Hiraishi, A., Y. K. Shin, Y. Ueda, and J. Sugiyama. 1994. Automated se- 
quencing of PCR-amplified 16S rDNA on "Hydrolink" gels. J. Microbiol. Methods 19:145-154.

12. Joyce, G. H., and P. R. Dugan. 1970 . The role of floc-forming bacteria in BOD removal from wastewater. Dev. Ind. Microbiol. 11:377-386.

13. Kimura, M. 1980. A simple method for estimating evolutionary rates of base substitutions through comparative studies of nucleotide sequences. J. Mol. Evol. 16:111-120.

14. Maidak, B. L., G. J. Olsen, N. Larsen, R. Overbeek, M. J. McCaughey, and C. R. Woese. 1997. The RDP (Ribosomal Database Project). Nucleic Acids Res. 25:109-110.

15. Mergaert, J., A. Schirmer, L. Hauben, M. Mau, B. Hoste, K. Kersters, D. Jendrossek, and J. Swings. 1996. Isolation and identification of poly(3hydroxyvalerate)-degrading strains of Pseudomonas lemoignei. Int. J. Syst. Bacteriol. 46:769-773.

16. Mitsui, H. Personal communication.

17. Rossello-Mora, R. A., W. Ludwig, and K. H. Schleifer. 1993. Zoogloea ramigera: a phylogenetically diverse species. FEMS Microbiol. Lett. 104:129134.

18. Saitou, N., and M. Nei. 1987. The neighbor-joining method: a new method for reconstructing phylogenetic trees. Mol. Biol. Evol. 4:406-425.

19. Shin, Y. K., A. Hiraishi, and J. Sugiyama. 1993. Molecular systematics of the genus Zoogloea and emendation of the genus. Int. J. Syst. Bacteriol. 43:826831.

20. Strand, S. E., A. J. McDonnell, and R. F. Unz. 1988. Oxygen and nitrate reduction kinetics of a nonflocculating strain of Zoogloea ramigera. Antonie van Leeuwenhoek 54:245-255.

21. Thompson, J. D., D. G. Higgins, and T. J. Gibson. 1991. CLUSTAL W: improving the sensitivity of progressive multiple sequence alignment through sequence weighting, position-specific gap penalties and weight matrix choice. Nucleic Acids Res. 22:4673-4680.

22. Unz, R. F. 1971. Neotype strain of Zoogloea ramigera Itzigsohn. Int. J. Syst. Bacteriol. 21:91-99.

23. Unz, R. F. 1984. Genus IV. Zoogloea Itzigsohn $1868,30^{\mathrm{AL}}$, p. $214-219$. In N. R. Krieg and J. G. Holt (ed.), Bergey's manual of systematic bacteriology, vol. 1. The Williams \& Wilkins Co., Baltimore, Md

24. Welsh, J., and M. McClelland. 1990. Fingerprinting genomes using PCR with arbitrary primers. Nucleic Acids Res. 18:7213-7218.

25. Willems, A., E. Falsen, B. Pot, E. Jantzen, B. Hoste, P. Vandamme, M. Gillis, K. Kersters, and J. De Ley. 1990. Acidovarax, a new genus for Pseudomonas facillis, Pseudomonas delafieldii, E. Falsen (EF) group 13, EF group 16, and several clinical isolates, with the species Acidovorax facilis comb. nov., Acidovorax delafieldii comb. nov., and Acidovorax temperans sp. nov. Int. J. Syst. Bacteriol. 40:384-398.

26. Willems, A., M. Gillis, K. Kersters, L. Van den Broecke, and J. De Ley. 1991. Polyphasic taxonomic study of the emended genus Comamonas: relationship to Aquaspirillum aquaticum, E. Falsen group 10, and other clinical isolates. Int. J. Syst. Bacteriol. 41:427-444.

27. Williams, J. G. K., A. R. Kubelik, K. J. Livak, J. A. Rafalski, and S. C. Tingey. 1990. DNA polymorphisms amplified by arbitrary primers are useful as genetic markers. Nucleic Acids Res. 18:6531-6535.

28. Yabuuchi, E., Y. Kosako, I. Yano, H. Hotta, and Y. Nishibuchi. 1995. Transfer of two Burkholderia and an Alcaligenes species to Ralstonia gen. nov.: proposal of Ralstonia pickettii (Ralston, Palleroni and Doudoroff 1973) comb. nov., Ralstonia solanacearum (Smith 1896) comb. nov. and Ralstonia eutropha (Davis 1969) comb. nov. Microbiol. Immunol. 39:897-904. 